\title{
FABRICAÇÃO DE CIRCUITOS ELETRÔNICOS PARA DESIGN DE INTERAÇÃO
}

Ricardo Santoro Weissenberg

Pontifícia Universidade Católica do Rio de Janeiro

rickweissenberg@gmail.com

Luiza Novaes

Pontifícia Universidade Católica do Rio de Janeiro

Inovaes@puc-rio.br

João de Sá Bonelli

Pontifícia Universidade Católica do Rio de Janeiro

joao@muare.net

Resumo: O Design de Interação é uma área emergente da prática do Design, mas seu ensino ainda é pouco explorado no Brasil. Neste trabalho exploramos ensino de Design de Interação a partir do conceito de prática reflexiva criado por Schön como princípio norteador para o desenvolvimento de projetos adequados às condições reais de um contexto social. No âmbito da prática reflexiva, o desenvolvimento práticoexperimental de projetos de Design de Interação é marcado pela forte relação interdisciplinar com as ciências tecnológicas, a partir da incorporação de conhecimentos de eletrônica e fabricação de circuitos no projeto e na prototipagem de dispositivos interativos. Neste projeto de pesquisa, exploramos técnicas de fabricação de circuitos eletrônicos tais como CNC, circuit etching, impressão de circuitos com tinta condutiva e estêncil em projetos de Design de Interação. São investigados os benefícios de se conhecer e explorar processos de produção de placas de circuito, assim como seus componentes eletrônicos e suas funções, no contexto da área de conhecimento do Design. A metodologia teve um caráter exploratório e experimental. Durante a pesquisa ficou evidenciada a adequação do processo de circuit etching aos objetivos do projeto. A pesquisa mostrou que a técnica é bastante pertinente em se tratando do ambiente de um laboratório de ensino de design, pois é simples, de fácil execução utilizando recursos facilmente acessíveis a alunos de design. Experimentos com fins didáticos foram realizados, com o objetivo de produzir materiais/kits que ofereçam para os alunos a oportunidade de utilização de sensores e atuadores eletrônicos em seus projetos de design. Desta forma contribuímos para integrar o conhecimento de eletrônica ao ensino de design, além de trazer a atenção dos alunos para novas oportunidades de atuação profissional.

Palavras-chave: Design de Interação, Interfaces Físicas, Placas de circuitos 